\title{
Prevalence and Predictors of Gestational Diabetes Mellitus among Pregnant Women Attending Fanara Family Center, in Egypt
}

\author{
Mohammed L. Salem*, Wael A. Zeid, and Mosleh A. Ismail \\ Department of Family Medicine, Faculty of Medicine, Suez Canal University, Egypt.
}

\begin{abstract}
Background: Gestational Diabetes Mellitus (GDM) is the most common metabolic disorder during pregnancy. It is associated with maternal and fetal complications. Screening for GDM and its risk factors is essential for the early diagnosis and management. Aim: This study aimed to improve pregnancy outcomes through assessing the prevalence and predictors of GDM among pregnant females attending Fanara family practice center between the $24^{\text {th }}$ and the $28^{\text {th }}$ weeks of gestation. Subjects and Methods: A cross-sectional study was conducted on 130 pregnant women. Non-probability consecutive sampling was applied to all patients who attended the antenatal care clinic in Fanara family practice center. The participants were interviewed using a structured questionnaire including socio-demographic scale and risk factors assessment. They were also subjected to physical examination and investigations. Results: The prevalence of GDM among included participants was estimated to be $6 \%$. Participants with GDM had a significantly higher mean maternal age compared to participants without GDM. The most common risk factors for GDM in the current study were family history of diabetes and prior history of abortion. Conclusion: Early detection of GDM and controlling of its risk factors are necessary for better maternal and fetal outcome.
\end{abstract}

Keywords: Pregnancy, Female health, Indicators

\section{Introduction}

Historically, Gestational diabetes mellitus (GDM) used to be defined as any degree of glucose intolerance with onset or first recognition during pregnancy ${ }^{(1)}$. Recently, the definition has evolved to distinguish women whose condition is a transient manifestation of pregnancy-related insulin resistance from those with probable preexisting diabetes that is first recognized during pregnancy ${ }^{(2,3)}$. The term GDM is used when diabetes mellitus is diag- nosed in the second half of pregnancy while it is named overt diabetes mellitus when diagnosed in the early pregnancy ${ }^{(4)}$. The prevalence of GDM varies from population to another ranging from 3 to $10 \%(5)$. In the United States (US), the prevalence of GDM is about 6 to $7 \%(6,7)$. In the Gulf Cooperation countries (GCC), the prevalence of GDM ranges from $4.2 \%$ and $24.9 \%{ }^{(8)}$. In Egypt, only 2 recent studies about GDM have been conducted in Upper Egypt and Delta region (Menoufia governorate $)^{(9)}$. In 2010, the International 
Association of Diabetes and Pregnancy Study Groups (IADPSG) implemented new criteria for screening and diagnosing $\mathrm{GDM}^{(10)}$. After using these criteria, the prevalence of hyperglycemia in pregnancy has been estimated at $17 \%$ globally varying between $10 \%$ in North America and $25 \%$ in Southeast Asia ${ }^{(11)}$. Many risk factors have been reported to increase the prevalence of GDM such as older age, previous GDM, body mass index (BMI) over $30 \mathrm{~kg} / \mathrm{m} 2$, family history of diabetes, previous macrosomic baby, and ethnicity of high prevalence, particularly South Asian, black Caribbean, and Middle Eastern(5). Other reported risk factors are history of polycystic ovary syndrome (PCOS), glycosuria in current pregnancy, history of chronic hypertension, and previous stillbirth ${ }^{(12)}$. GDM is associated with poor pregnancy outcomes such as preeclampsia, hydramnios, macrosomia, large for gestational age infant, fetal organomegaly, maternal and infant birth trauma, operative delivery, perinatal mortality, and neonatal respiratory and metabolic complications ${ }^{(13)}$. Also, women with GDM are at increased risk of developing type 2 diabetes(4). Significantly, the risks of these outcomes increase as maternal fasting plasma glucose levels rise above $75 \mathrm{mg} / \mathrm{dL}(4.2 \mathrm{mmol} / \mathrm{L})$. This is a continuous relation and there is no clear threshold that defines patients at increased risk of adverse obstetrical outcome ${ }^{(14)}$. Screening for GDM and its risk factors are essential for the early diagnosis and management of GDM patients, which helps in the improvement of pregnancy outcomes. The treatment of GDM has been reported to reduce some of the pregnancy and neonatal complications such as preeclampsia and fetal macrosomia(15). To the best of our knowledge, studies regarding the screening of GDM and its risk factors in Egypt are scant. With the lack of nationwide figures, this study aimed to provide local epidemiological data about GDM and its risk factors, which can be used to develop nationwide estimates.

\section{Subjects and Methods}

This cross-sectional study was carried out at Fanara family practice center in Fanara village. Fanara village is located in Ismailia governorate, about $40 \mathrm{Km}$ south to Ismailia city, Egypt. It consists of 52 manors with population size around 12500.The majority of its populations work in fishing. Fanara family practice center is located in the center of Fanara village, providing different medical services at the level of the primary health care e.g. chronic disease care and women health. The study setting was chosen as it is the work place of the researcher, so it was easier to recruit the study participants. The study was conducted on 130 pregnant women attending Fanara family practice center according to the following inclusion criteria: 1) Pregnant women aged 18-49 years, 2) Gestational age ranging from 24 to 28 weeks, and 3) Accepting to participate in the study and give voluntary informed consent. Pregnant women with any of the following were exclude from the study: 1) known diabetes mellitus, or 2) any chronic illness (because they are high risk patients who require early screening at first prenatal visit. Non-probability consecutive sampling was applied. All patients who attended the antenatal care clinic in Fanara family medicine center from March 2018 to November 2018 and fulfilled the eligibility criteria were enrolled until reaching the estimated sample size.

\section{Methods:}

1- A questionnaire which consists of 2 parts: A- Socio-demographic data: Using a valid socioeconomic scale. This scale includes 7 domains which are: education and cultural domain, education domain, family possessions domain, family domain, 
home sanitation domain, economic domain, and health care domain. The total score is $\mathbf{8 4}$, according to which the socioeconomic level was classified into very low, low, middle, and high levels depending on the quartiles of the score calculat$\mathrm{ed}^{(17)}$. B- Risk factors assessment: Including obstetric history, life-style habits (as smoking), medical history which includes: Chronic diseases (as diabetes, hypertension) and drug intake, and previous operations. Other risk factors of the disease involving $\mathrm{BMI}$ before pregnancy, blood pressure measurement, previous history of Large size baby ( $4 \mathrm{~kg}$ or more), past history of pre-eclampsia, and previous history of still birth or abortions. This questionnaire has been validated by doing a pilot study.

2- Physical examination included Height, Weight and Blood pressure.

3- Lab. investigations: "Two step method for diabetes mellitus assessment was chosen, as it is more practical because it is not essential that all participants should be fasting to undergo the test, compared to the " 1 step " method. Initial screening was done by a glucose challenge test with $50 \mathrm{~g}$ glucose. If the 1-hour blood glucose level exceeds $140 \mathrm{mg} / \mathrm{dl}$, then a 3-hour oral glucose tolerance test (OGTT) with $100 \mathrm{~g}$ glucose was performed and diagnosis has been established according to American
Diabetes Association criteria. At the 140 $\mathrm{mg} / \mathrm{dL}$ threshold, the specificity was higher $(69 \text { to } 89 \%)^{(18)}$. The following are the values which the American Diabetes Association considers to be abnormal during the 100 g OGTT: [Fasting plasma glucose level $\geq 105 \mathrm{mg} / \mathrm{dl}$, 1-hour plasma glucose level $\geq 190 \mathrm{mg} / \mathrm{dl}$, 2-hours plasma glucose level $\geq 165 \mathrm{mg} / \mathrm{dl}$ and 3 -hours plasma glucose level $\geq 145 \mathrm{mg} / \mathrm{dl}]$. 2 or more criteria must be met or exceeded for a positive diagnosis ${ }^{(19)}$.

\section{Operational Design}

Pilot study: After preparation of the risk factors assessment questionnaire form, it was pretested on 10 patients before the beginning of data collection to assess the relevance and understandability of the questions. The researcher has applied any necessary modifications. The piloted sample was not included in the main study sample.

Field work: All participants were subjected to: 1- Building initial rapport. 2- Taking a written consent. 3- Filling the two parts of questionnaire by the researcher. Time was taken to fill this questionnaire about 15 minutes. 4- Doing physical examination which includes measuring height, weight, and blood pressure. 5- Performing laboratory investigation in form of two step method of OGTT.

Table 1: Demographic and clinical characteristics of the participants $(n=130)$.

\begin{tabular}{|c|c|c|}
\hline \multicolumn{3}{|l|}{ Variables } \\
\hline Age (years) Mean \pm SD & \multicolumn{2}{|c|}{$26.47 \pm 4.41$} \\
\hline $\begin{array}{l}\text { Social class: } \\
\text { - } \quad \text { Very low } \\
\text { - } \quad \text { Low } \\
\text { - } \quad \text { Moderate } \\
\end{array}$ & $\begin{array}{c}\text { No } \\
9 \\
112 \\
9\end{array}$ & $\begin{array}{c}(\%) \\
(7 \%) \\
(86 \%) \\
(7 \%)\end{array}$ \\
\hline $\begin{array}{ll}\text { Clinical assessment: Mean } \pm \text { SD } \\
\text { - } & \text { Systolic blood pressure }(\mathrm{mmHg}) \\
\text { - } & \text { Diastolic blood pressure }(\mathrm{mmHg}) \\
\text { - } & \text { Height }(\mathrm{cm}) \\
\text { - } & \text { Weight }(\mathrm{kg}) \\
\text { - } & \text { BMI }(\mathrm{kg} / \mathrm{m} 2)\end{array}$ & & $\begin{array}{l}15.76 \\
8.79 \\
5.14 \\
5.14 \\
3.58\end{array}$ \\
\hline
\end{tabular}

$\mathrm{SD}=$ Standard Deviation; $\mathrm{BMI}=$ Body mass index 


\section{Statistical Analysis}

The collected data were coded, entered, presented, and analyzed by computer using a data base software program, Statistical Package for Social Science (version 20, SPSS Inc., Chicago, IL). Quantitative variables were expressed as the mean \pm standard deviation (SD) while the qualitative variables were expressed as a number and percentage. For quantitative variables, Independent samples t-test ( $t$ ) was used as appropriate for normally distributed data. Chi square and or Fisher's exact tests were used to detect the relation between different qualitative variables. The results were considered statistically significant when the significant probability $(p<0.05)$.
Ethical consideration

The study procedures were approved by the ethical committee of the Faculty of Medicine, Suez Canal University and the Family Medicine Dept. A written informed consent was voluntarily sought from the participants, after clarifying the aim, methods and duration of the study. Confidentiality of data was ensured by keeping the questionnaire and blood samples anonymous and data were only accessed by the researcher. Potential risks were minimized (i.e. decreasing the volume of blood samples, and the use of qualified personnel. Study participants had the right to withdraw from the study at any time without giving reasons and without negatively affecting their medical care.

Table 2: Laboratory results and frequency of GDM among the studied participants $(\mathrm{n}=130)$.

\begin{tabular}{|l|c|c|}
\hline Variables & No & $(\%)$ \\
\hline 1-hour glucose (non-fasting) challenge test: & & \\
- $\quad 2140(\mathrm{mg} / \mathrm{dL})$ & 22 & $(16.9 \%)$ \\
- $\quad 140(\mathrm{mg} / \mathrm{dL})$ & 108 & $(83.1 \%)$ \\
\hline OGTT in Female with 1-hour glucose $\geq 140(\mathrm{mg} / \mathrm{dL}):$ & & \\
- Fasting blood glucose > 95 (mg/dL) & 9 & $(6.9 \%)$ \\
- $\quad$ 1-hour OGTT > 180 (mg/dL) & 3 & $(2.3 \%)$ \\
- 2-hour OGTT > 155 (mg/dL) & 6 & $(4.6 \%)$ \\
- 3-hour OGTT > 140 (mg/dL) & 4 & $(3.1 \%)$ \\
\hline American Diabetes Association criteria ( $\geq 2$ of the 4-cut point): & & \\
- Female with GDM & 8 & $(6 \%)$ \\
- Female without GDM & 122 & $(94 \%)$ \\
\hline
\end{tabular}

OGTT=Oral glucose tolerance test; challenge test $=50$ gm glucose; OGTT= (100 gm glucose $)$

\section{Results}

A total of 130 pregnant females agreed to participate in this study with gestational age ranging from 24 to 28 weeks attending Fanara family practice center. The mean age of the included participants was $26.47 \pm 4.41$ years and most of them had low social class ( $86 \%)$, while there were no detected participants with high level. The participants were assessed clinically by measuring their blood pressure, as well as, their height and weight, and the BMI were calculated accordingly. The mean systolic and diastolic blood pressures were (106 \pm 15) $\mathrm{mmHg}$ and $(70 \pm 8) \mathrm{mmHg}$ respectively, while their mean height and weight were $(162.66 \pm 5.14) \mathrm{cm}$ and $(80.41 \pm 5.14) \mathrm{kg}$, respectively. Furthermore, the calculated mean BMI was $(27.25 \pm 3.58) \mathrm{kg} / \mathrm{m} 2$ (Table 1). Laboratory results and frequency of GDM among the studied participants shows that the laboratory results of the participants, where 22 pregnant females 
(16.9\%) had their 1-hour glucose nonfasting challenge test more than 140 $\mathrm{mg} / \mathrm{dL}$. Afterwards, on conducting OGTT, we found that percent of females glucose levels at fasting $>95(\mathrm{mg} / \mathrm{dL}), 1$-hour $>180$ ( $\mathrm{mg} / \mathrm{dL})$, 2-hour $>155(\mathrm{mg} / \mathrm{dL})$, and 3-hour $>140(\mathrm{mg} / \mathrm{dL})$ after receiving $100 \mathrm{gm}$ glucose were (6.9\%), (2.3\%), (4.6\%), and (3.1\%) respectively, where only 8 patients (6\%) have fulfilled American Diabetes Associa- tion criteria to have GDM (Table 2). Regarding the relationship between demographic characteristics and GDM status, the mean age of pregnant females with GDM (29 \pm 3.1$)$ years was significantly higher than non-diabetic ones $(26.3 \pm 4.5)$ years $(p<0.05)$. However, there was no statistically significant difference $(p \geq 0.05)$ between both groups regarding social class distribution (Table 3).

Table 3: Relation between demographic characteristics and Gestational Diabetes Mellitus status among the studied participants $(n=130)$.

\begin{tabular}{|c|c|c|c|c|c|c|}
\hline Variables & \multicolumn{2}{|c|}{$\begin{array}{c}\text { Non GDM } \\
(\mathrm{n}=122)\end{array}$} & \multicolumn{2}{|c|}{$\begin{array}{c}\text { Non GDM } \\
(n=8)\end{array}$} & Test & $P$ value \\
\hline Age (years): mean $\pm{ }^{\text {a }} S D$ & \multicolumn{2}{|c|}{$26.3 \pm 4.5$} & \multicolumn{2}{|c|}{$29 \pm 3.1$} & $b_{130.5}$ & $0.032 *$ \\
\hline $\begin{array}{l}\text { Social class: No (\%) } \\
\text { - Very low } \\
\text { - } \quad \text { Low } \\
\text { - } \quad \text { Moderate }\end{array}$ & $\begin{array}{c}8 \\
107 \\
7\end{array}$ & $\begin{array}{c}(7 \%) \\
(87.7 \%) \\
(5.3 \%)\end{array}$ & $\begin{array}{l}1 \\
5 \\
2\end{array}$ & $\begin{array}{c}(12.5 \%) \\
(62.5 \%) \\
(25 \%)\end{array}$ & ${ }^{c} 4.96$ & 0.098 \\
\hline
\end{tabular}

${ }^{\mathrm{a}}$ Standard Deviation; ${ }^{\mathrm{b}}$ Independent $\mathrm{t}-\mathrm{Test} ;{ }^{\mathrm{c}}$ Chi square test $\left(\mathrm{X}^{2}\right) ;{ }^{*} p$ value $<0.05$

Table 4: Relation between potential risk factors and Gestational Diabetes Mellitus status among the studied participants $(\mathrm{n}=130)$.

\begin{tabular}{|c|c|c|c|c|c|}
\hline \multirow[t]{2}{*}{ Variables } & \multicolumn{2}{|c|}{$\begin{array}{l}\text { Non GDM } \\
(\mathrm{n}=122)\end{array}$} & \multicolumn{2}{|c|}{$\begin{array}{l}\text { Non GDM } \\
(\mathrm{n}=8)\end{array}$} & \multirow[t]{2}{*}{${ }^{\mathrm{c} P}$ value } \\
\hline & No & $(\%)$ & No & $(\%)$ & \\
\hline - Family history of diabetes & 38 & $(31.6 \%)$ & 4 & $(50 \%)$ & 0.67 \\
\hline - History of hypertension & 9 & $(7.3 \%)$ & 0 & $(0.0 \%)$ & 0.73 \\
\hline - History of ${ }^{a}$ GDM & 2 & $(1.6 \%)$ & 1 & $(12.5 \%)$ & 0.33 \\
\hline - Previous macrosomic baby & 9 & $(7.3 \%)$ & 1 & $(12.5 \%)$ & 0.38 \\
\hline - History of gestational hypertension & 9 & $(7.3 \%)$ & 0 & $(0.0 \%)$ & 0.73 \\
\hline - History of prior abortions & 28 & $(22.9 \%)$ & 2 & $(25 \%)$ & 0.99 \\
\hline - History of stillbirth & 2 & $(1.6 \%)$ & 1 & $(12.5 \%)$ & 0.33 \\
\hline - History of neonatal deaths & 2 & $(1.6 \%)$ & 1 & $(12.5 \%)$ & 0.33 \\
\hline $\begin{array}{l}\text { - History of babies with congenital } \\
\text { abnormalities }\end{array}$ & 2 & $(1.6 \%)$ & 0 & $(0.0 \%)$ & 0.99 \\
\hline - History of obesity & 1 & $(0.8 \%)$ & 3 & $(37.5 \%)$ & $0.02 *$ \\
\hline - History of ${ }^{\mathrm{b}} \mathrm{PCOS}$ & 9 & $(7.3 \%)$ & 1 & $(12.5 \%)$ & 0.81 \\
\hline
\end{tabular}

${ }^{a}$ Gestational Diabetes Mellitus; ${ }^{b}$ Polycystic ovary syndrome; ${ }^{c}$ Fisher's exact test; * $P$ value $<0.05$

The relation between potential risk factors and GDM status among the studied participants shows the relationship between the potential risk factors and the GDM status among the pregnant women in both groups, where the most prevalent risk factor in both groups was family history of diabetes (50\% in GDM group and $31.6 \%$ in the non- GDM group), whereas pregnant females with GDM was associat- 
ed with more history of obesity than normal females with statistically significant difference $(p<0.05)$ (Table 4). Logistic regression analysis was used to assess predictors of GDM among the pregnant women. Multivariate analysis for the potential risk factors of GDM among the pregnant women showed that the bestfitting predictors of GDM among the pregnant women were older maternal age and females with previous history of obesity. To explain, for every 1 unit increase in maternal age, the odds of occurrence of GDM increase by $15.7 \%(p<0.05)$. Moreover, pregnant females with $\mathrm{BMI}>30$ were 1.19 times more likely to have gestational diabetes than those with BMI less than 30 $(p<0.05)$ (Table 5).

Table 5: Multivariate analysis for the potential risk factors of Gestational Diabetes Mellitus among the pregnant women

\begin{tabular}{|c|c|c|c|}
\hline Variables & $\beta\left(S E^{b}\right)$ & $\mathrm{OR}\left(95 \% \mathrm{Cl}^{\mathrm{c}}\right)$ & $p$ value \\
\hline Constant & $4.36(3.81)$ & & 0.013 \\
\hline Age & $0.157(0.11)$ & $1.17(0.93-1.47)$ & $0.039 *$ \\
\hline Number of previous labors & $0.24(0.47)$ & $1.272(0.51-3.21)$ & 0.61 \\
\hline History of GDM ${ }^{a}$ & $-0.63(1.42)$ & $0.526(0.32-8.59)$ & 0.65 \\
\hline Previous macrosomic baby & $1.113(1.65)$ & $3.04(0.12-39.71)$ & 0.5 \\
\hline History of stillbirth & $2.87(1.72)$ & $17.76(0.53-56.74)$ & 0.11 \\
\hline History of obesity & $0.18(1.72)$ & $1.19(0.9-3.85)$ & $0.027^{*}$ \\
\hline
\end{tabular}

\section{Discussion}

A cross-sectional study was conducted to assess the prevalence of GDM among pregnant women between 24 and 28 weeks of gestation and to identify its potential risk factors. Pregnant women attending Fanara family practice center, were recruited. "Two step" method has been chosen as addressed in the methods section, as it is more practical because it is not essential that all participants were stayed 2-3 hours to complete the test, compared to the " 1 step " method and no need for fasting for the first step of it. According to the American Diabetes Association diagnostic criteria, the prevalence of GDM among the included participants was estimated to be $6 \%$. A similar study was conducted in Egypt on 250 pregnant women, in which an eight percent prevalence of GDM was reported(9). However, variations in the reported prevalence of GDM have been found; $15.9 \%$ by Mohan and Chandrakumar, using the World
Health Organization (WHO) criteria, (20), $16.2 \%$ and $51 \%$ by Alfadhli et al., using the American Diabetes Association and the International Association of the Diabetes and Pregnancy Study Groups (IADPSG) respectively ${ }^{(21)}$ and $4 \%$ by Kanadys, using the Polish Diabetes Association recommendations ${ }^{(22)}$. These variations could be explained by the differences in the sociodemographic characteristics of the studied populations, the sample size, and the applied diagnostic criteria. It should also be noted that the global prevalence of GDM has been reported to be widely variable (1-28\%) due to ethnic heterogeneity among different tested populations ${ }^{(2)}$. Regarding the socio-demographic characteristics in the current study, participants with GDM had a significantly higher mean maternal age $(p<0.05)$ compared to participants not diagnosed with GDM. Similarly, the prevalence of GDM has been reported to increase with increasing maternal age $(20,21,23)$. Interestingly, $A$ maternal age below 30 years was identified as the 
optimum pregnancy period where the risk of GDM was reduced ${ }^{(23)}$. In relation to the social class, there was no statistically significant difference $(p \geq 0.05)$ between pregnant females with GDM and nondiabetic ones. In this context, Khalil et al., found that socio-economic class was not statistically different between the 2 groups $^{(9)}$. Yet, Mohan and Chandrakumar, reported that patients with GDM were of a significantly higher socio-economic class compared to those without $\mathrm{GDM}^{(20)}$. Erem et al., found that the woman's occupation and household income were insignificantly related to GDM. They clarified that women with higher level of education and higher income were more likely to do a sedentary work that may possibly result in obesity and $\mathrm{GDM}^{(23)}$. However, most of our patients were of low socio-economic status; they just met their routine expenses, didn't receive governmental support and didn't pay taxes neither, therefore, we couldn't detect a significant difference. The most common risk factors for GDM among our patients were a family history of diabetes and a prior history of abortion. This was consistent with the findings of 2 previous studies ${ }^{(24,25)}$. When comparing patients with GDM patients to women not diagnosed with GDM, only the history of obesity was found to be significantly different $(p \geq 0.05)$ between the 2 groups, where patients with GDM had a higher history of obesity. Meanwhile, other risk factors showed no significant difference $(p \geq 0.05)$ between the 2 groups. However, in multivariate analysis, maternal age and obesity were found to be independent risk factors for GDM among pregnant women. Similarly, Ali et al., reported that age was a significant risk factor for GDM; however, they also found that family history of diabetes, previous $G D M$, and history of PCOS were independent risk factors for $\mathrm{GDM}^{(24)}$. In addition, other significant risk factors for GDM have been proposed in other studies, including family history of diabetes in firstdegree relatives, previous history of GDM, (23) history of delivering a big baby, ${ }^{(20)}$ history of delivering a malformed child, (21) presence of hypertension, previous history of pre-eclampsia, previous history of induced labor or abortion ${ }^{(9)}$. The current study had some limitations. Because of the non-probability-sampling method, the results of the sample could not be generalized to the total population. Moreover, many aspects of our data, except for the clinical and lab results, were based on women's recall and were not obtained from medical records; thus, these data might be subjected to recall bias.

\section{Conclusion}

The prevalence of GDM was found to be six percent among pregnant females attending Fanara family practice center. Early detection of GDM and controlling of its risk factors are necessary for better maternal and fetal outcome.

\section{Acknowledgment}

The authors would like to thank all participants subjected to this study.

\section{Authors' contributions}

All authors had contributed to the study conception and design. Material preparation, data collection and analysis were performed by [Salem ML, Zeid WA and Ismail MA]. The manuscript was written by [Salem ML] and all authors had read and approved the final manuscript.

\section{Funding}

The authors received no grants, equipments, or drug support for the authorship, and/or publication of this article

\section{References}

1. Alberti K, Zimmet P. Definition, diagnosis and classification of diabetes melli- 
tus and its complications. Part 1: diagnosis and classification of diabetes mellitus. Provisional report of a WHO Consultation. Diabetic Med 1998; 15(7):539-553.

2. Hod M, Kapur A, Sacks DA, et al. The International Federation of Gynecology and Obstetrics (FIGO) Initiative on gestational diabetes mellitus: A pragmatic guide for diagnosis, management, and care. IJGO 2015; 131(S3): 173-211.

3. American Diabetes Association. Classification and diagnosis of diabetes: standards of medical care in diabetes. Diabetes care 2018 Jan 1; 41 (Supplement 1): S13-27.

4. Coustan MD. Diabetes mellitus in pregnancy: Screening and diagnosis. In Barss V, ed. UpToDate 2017. Waltham, MA: UpToDate Inc. http://www. uptodate. com Accessed 20 January 2017.

5. American Diabetes Association. Gestational diabetes mellitus. Diabetes care 2004 Jan 1; 27(suppl 1): s88-90.

6. Hartling L, Dryden DM, Guthrie A, et al. Screening and diagnosing gestational diabetes mellitus. Evidence Report/Technology Assessment Oct 2012; (210):1.

7. U.S. Preventive Services Task Force Recommendation Statement. Screening for Gestational Diabetes Mellitus. Ann Intern Med 2008; 148(10):759.

8. Barakat MN, Youssef RM, Al-Lawati JA. Pregnancy outcomes of diabetic women: Charting Oman's progress towards the goals of the Saint Vincent Declaration. Ann Saudi med. 2010; 30(4):265.

9. Khalil N. Screening for Gestational Diabetes Among Pregnant Women Attending a Rural Family Health CenterMenoufia Governorate- Egypt. JFMHC 2017; 3(1):6.

10. International Association of Diabetes and Pregnancy Study Groups. Recommendations on the Diagnosis and Classification of Hyperglycemia in Pregnancy. Diabetes Care 2010; 33(3):676-682.

11. Guariguata L, Whiting DR, Hambleton I, Beagley J, Linnenkamp U, Shaw JE. Global estimates of diabetes preva- lence for 2013 and projections for 2035 . Diabetes Res Clin Pract. 2014; 103(2):137-149.

12. Ashrafi $M$, Sheikhan $F$, Arabipoor A, Hosseini R, Nourbakhsh F, Zolfaghari Z. Gestational diabetes mellitus risk factors in women with polycystic ovary syndrome (PCOS). Eur J Obstet Gynecol Reprod Biol 2014; 181:195-199.

13. Dodd J, Crowther C, Antoniou G, Baghurst $P$, Robinson J. Screening for gestational diabetes: The effect of varying blood glucose definitions in the prediction of adverse maternal and infant health outcomes. Aust N Z J Obstet Gynaecol 2007; 47(4):307-312.

14. Farrar D, Simmonds M, Bryant M, Sheldon T, Tuffnell D, Golder S. Hyperglycaemia and risk of adverse perinatal outcomes: systematic review and meta-analysis 2016; BMJ 13; 354: i4694.

15. Landon MB, Spong CY, Thom E, et al. A multicenter, randomized trial of treatment for mild gestational diabetes. $\mathrm{N}$ Engl J Med 2009; 361(14):1339-1348.

16. Dawson B, Trapp RG Eds. Basic and Clinical Biostatistics. 4th Edition, McGraw-Hill Professional, New York, 2004.

17. El-Gilany A, El-Wehady A, El-Wasify M. Updating and validation of the socioeconomic status scale for health research in Egypt. East. Mediterr Health J. 2012; 18(9):962-968.

18. Donovan L, Hartling L, Muise M, Guthrie $A$, Vandermeer $B$, Dryden $D$. Screening Tests for Gestational Diabetes: A Systematic Review for the U.S. Preventive Services Task Force. Ann Intern Med 2013; 159(2):115.

19. Marathe P, Gao H, Close K. American Diabetes Association Standards of Medical Care in Diabetes 2017. J Diabetes 2017; 9 (4):320-324.

20. Mohan MA, Chandrakumar A. Evaluation of prevalence and risk factors of gestational diabetes in a tertiary care hospital in Kerala. Diabetes and Metabolic Syndrome: Clin Res Rev 2016; 10(2): 68-71. 
21. Alfadhli EM, Osman EN, Basri TH, et al. Gestational diabetes among Saudi women: prevalence, risk factors and pregnancy outcomes. Ann Saudi Med 2015; 35(3):222-230.

22. Kanadys WM. Occurrence of gestational diabetes mellitus: prognostic value of diabetes risk factors. Arch Perinatal Med 15 2009; (2):106-111.

23. Erem C, Kuzu UB, Deger O, Can G. Prevalence of gestational diabetes mellitus and associated risk factors in Turkish women: The Trabzon GDM Study. Arch Med Sci 2015; 11(4):724-735.

24. Ali AD, Mehrass AA, Al-Adhroey AH, AlShammakh AA, Amran AA. Prevalence and risk factors of gestational diabetes mellitus in Yemen. Int J Women Health 1998; 8:35.

25. Saeed J, Hasan A, Bakhsh AR. Assessment of Gestational Diabetes Mellitus Risk Factors in Local Population. Int J Endorsing Health Sci Res (IJEHSR), 2016; 4(4):19-27. 